\title{
FABAC Accelerated Loading Test of Bond between Cement Overlay and Asphalt Layers
}

\author{
A. Chabot \\ Division Matériaux et Structures de Chaussées - LCPC, Bouguenais, France
}

B. Pouteau

Eurovia Management, Merignac, France

J. M. Balay

Division Matériaux et Structures de Chaussées/LCPC, Bouguenais, FRANCE

F. de Larrard

Direction Scientifique/LCPC, Bouguenais, FRANCE

\begin{abstract}
This paper focuses on an experimental mechanical study of the bond fatigue life of composite (concrete over asphalt) pavements. This in-situ experiment is based on the use of an accelerated pavement testing facility (FABAC fatigue device). With the support of the French cement industry, a pavement section similar to an Ultra Thin White-topping structure has been realized at the LCPC-Nantes Center. Vertical joints of plain concrete have been loaded up to one million cycles. A non destructive seismic method, COLIBRI device, has been used to follow the interface debounding. Combined with core observations, it is possible to propose the accelerated fatigue damage scenario of such a composite pavement. The bond as well as the layers has been damaged by fatigue. These damages depend on temperature conditions wheel positions and interface treatments. Specific modeling and laboratory fatigue tests are proposed to be developed to deepen the knowledge of these deteriorations.
\end{abstract}

\section{INTRODUCTION}

Since 1990's, composite pavement structures have been raising a significant interest. Among these structures, those based on the association of a concrete overlay bonded to an existing asphalt sub-base are studying in this paper. Assuming a long lasting bond between these layers allows a reduction of layer thickness and therefore a reduction of construction costs (Cole et al., 1998). However, due to a lack of feedback, the durability of this bond under traffic condition is not granted. Previous studies have concluded that the weakness of the bond is located in the vicinity of vertical shrinkage cracks of cement concrete overlay (Pouteau et al., 2002). It is well known that the different elastic properties of the two media combined to the vertical crack down to the interface leads to theoretical stress singularities (Chabot et al., 2005). In practice, stress concentrations are expected and need to be studied in these zones (Fig. 1).

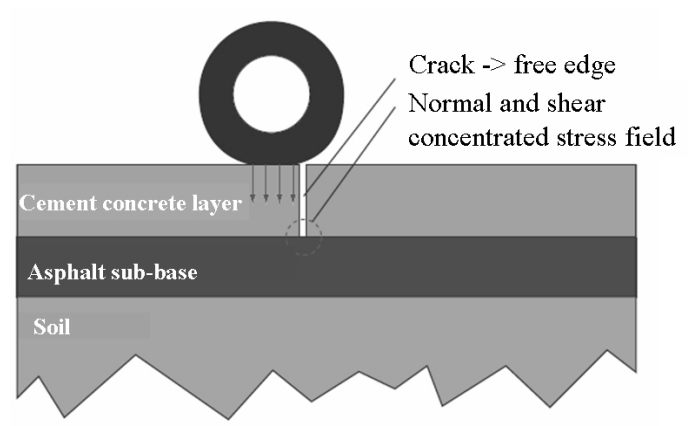

Figure1. Location of stress singularities at the interface near a crack on a loaded composite pavement structure 
In 2001, due to a lack of long-lasting bond life data, the French government and the cementer industry proposed to launch a study aiming to a better prediction of lifetime of these composite pavement structures. This paper gives an overview of the in-situ accelerated loading pavement study that has been carried on during 2003 in relation to the PhD CIFRE ATILH Pouteau thesis (Pouteau, 2004) (Pouteau et al., 2004b) on composite pavements similar to Ultra-Thin White-topping (UTW) ones (CIMbéton, 2004) (Qi et al., 2004).

First the experimental study is presented. Then, results coming from non-destructive and destructive investigations are given. They lead to propose the damage scenario that has been probably occurred. Finally, specific modeling considerations are noticed before conclude.

\section{ACCELERATED LOADING PAVEMENT STUDY}

At LCPC - Nantes Centre, the large circular Accelerated Loading Facilities (ALF), "Manège de fatigue" (Autret et al., 1987), can produce interesting fatigue pavement results (Hornych et al., 2008) but these tests are relatively expensive. For such an in-situ bond fatigue life study, the two linear ALF, called FABAC (Aunis \& Balay 1998), offer an alternative solution at lower cost.

First, the FABAC machines are described. Then the composite pavement test section and its instrumentation are given before presenting the accelerated loading tests conditions.

\subsection{FABAC Accelerated Loading Facility (ALF)}

The two FABAC ALF are small heavy traffic simulators built in 1995. The two machines are similar enough, making it possible to test simultaneously two experimental pavement structures or surface layer under quite identical loading and environmental conditions. Each machine has four load modules. They are carried by a chain to apply the load along $2 \mathrm{~m}$ of the test track without lateral wandering (Fig. 2). The weight applied to each load module (twinned or single wheel) varies from 30 to $75 \mathrm{kN}$. The wheel speed varies from 0.5 to $7 \mathrm{~km} / \mathrm{h}$ and the maximal load frequency is 50 loads per minute. The cumulated traffic is between 200000 and 320000 loadings weekly (http://www.lcpc.fr/fr/presentation/organigramme/div_msc/equip/fabac.php).

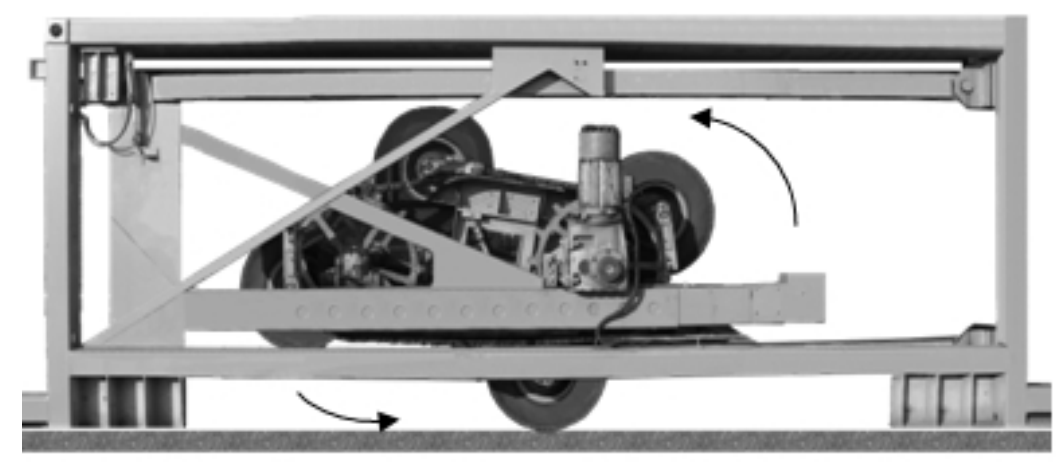

Figure 2. The FABAC machine, general view

FABAC machine main characteristics are: overall length $11.20 \mathrm{~m}$; overall width $2.50 \mathrm{~m}$; total weight $173 \mathrm{kN}$; electrical power $50 \mathrm{kVA}$; complementary equipment : halogen heating system $\left(25 \mathrm{kVA}\right.$ ) for temperature control in the tested pavement (maximal temperature $70^{\circ} \mathrm{C}$ ).

\subsection{Composite pavement test section and instrumentation of the accelerated loading test}

The pavement test section has been first designed with the help of the French ALIZE software and standard materials of its library. This calculus gives rather good global elastic pavement response although it uses the axisymetric elastic Burmister modelling (1943) that can not take into account pavement discontinuities and the visco-elastic behaviour of asphalt material either. This pavement test section has been designed to get the greater interface shear rate between twin wheels. According to the French design method (LCPC-SETRA, 1994) and to bonding or not 
assumptions, the pavement test section was expected to resist to more than 1 million cycles of loadings for a $10 \mathrm{~cm}$ asphalt layer thickness (Pouteau, 2004a) (Pouteau et al., 2006a).

The composite pavement test section has been built on a $27.5 \mathrm{~m}$ long and $2 \mathrm{~m}$ width track. 9 joints $(0.5 \mathrm{~mm}$ width) have been realized through the middle of the thickness of the cement concrete overlay. It produced 10 slabs with $2.75 \mathrm{~m}$ long and $1.95 \mathrm{~m}$ width (Fig. 3). This test section is composed of three kinds of joints: (i) shot blasted interface, (ii) no specific interface treatment, (iii) delaminated interface. This last type of joint has been obtained by using a plastic membrane interposed between the two layers to provide a slippery interface. Standard French twinned wheels have been used (0.662MPa per wheel separated from $0.375 \mathrm{~m}$ each other). Experimental measurements gave an average $0.18 \times 0.28 \mathrm{~m}^{2}$ contact area for each.

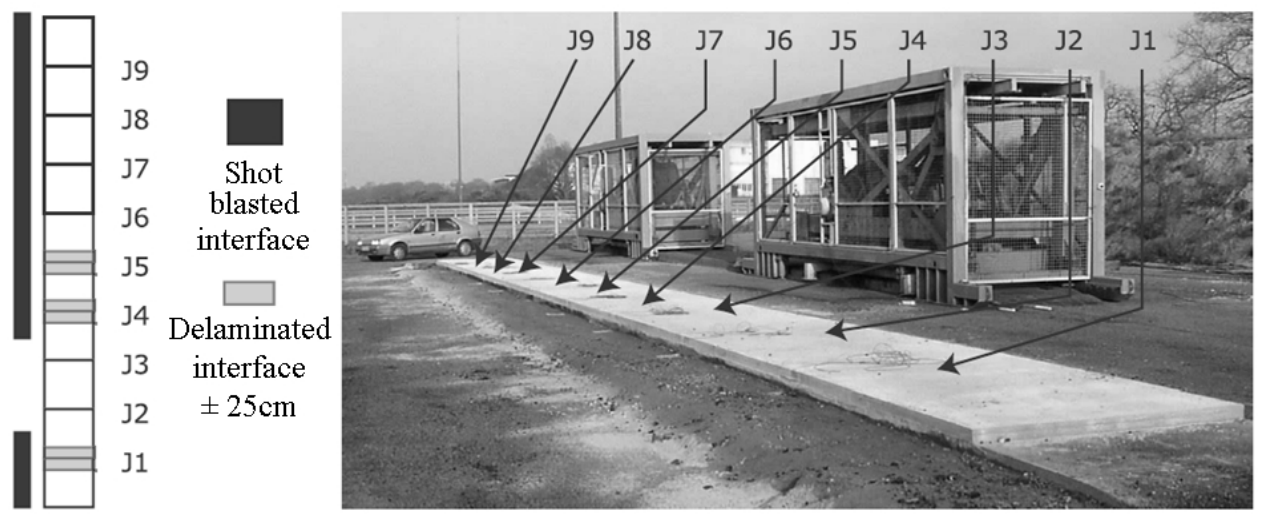

Figure3. The composite pavement test section and the two FABAC machines (Pouteau, 2004a)

Similar to UTW structures, this pavement test section was built with a $0.08 \mathrm{~m}$ cement concrete (BC) thickness overlay $(E=32600 M P a ; v=0.35)$ on a new $0.95 \mathrm{~m}$ asphalt material (GB3) thickness sub-base. This composite structure lays on a $0.15 \mathrm{~m}$ sand cement thickness capping layer so that this bi-material structure is assumed to be supported by an equivalent soil with a $120 \mathrm{MPa}$ modulus and a $v=0.35$ Poison ratio. Table 1 details the material characteristics and in situ control procedures.

Table1. Materials characteristic of the test pavement section

\begin{tabular}{lll}
\hline Material & Theoretical mixes & In-situ control \\
\hline Sand cement & & Density: $94.7 \%(\mathrm{OPM})$ \\
$\begin{array}{l}\text { Asphalt material } \\
\text { (GB3) }\end{array}$ & $\begin{array}{l}\text { Particle size distribution : } 0 / 14 \\
\text { Pure bitumen grade: } 35 / 50\end{array}$ & $\begin{array}{l}\text { Average thickness: } 9.6 \mathrm{~cm} \\
\text { Void content: } 7 \%\end{array}$ \\
& $\begin{array}{l}\text { Binder content: } 4.3 \% \\
\text { Fatigue 1million strain value: } \varepsilon_{c}=91.10^{-6}\end{array}$ \\
Cement concrete & Particle size distribution : $0 / 14$ & \\
(BC) & Type I Portland (CEM I 52.5): $255 \mathrm{~kg} / \mathrm{m}^{3}$ & Average thickness: $8 \mathrm{~cm}$ \\
& Filler: $55 \mathrm{~kg} / \mathrm{m} 3$; Water: $156 \mathrm{~kg} / \mathrm{m}^{3}$ & air content: $4,8 \%$ \\
& 28 days slitting tension strength: $3.3 \mathrm{MPa}$ & Slump: $3.5 \mathrm{~cm}$ \\
& 28 days compression strength: $32.6 \mathrm{MPa}$ & \\
\hline
\end{tabular}

For the asphalt material modulus characterization, Huet-Sayegh model (1963) fits rather good visco-elastic behavior predictions of experimental data. Equation 1 summarizes its complex modulus that depends on the frequency $\omega$ and the temperature $\theta$ :

$$
E^{*}(\omega, \theta)=E_{0}+\frac{E_{\infty}-E_{0}}{1+\delta(j \omega \tau(\theta))^{-k}+(j \omega \tau(\theta))^{-h}}
$$

with $\tau(\theta)=\exp \left(A_{0}+A_{1} \theta+A_{2} \theta^{2}\right)$ a function of the temperature and three scalar parameters $\mathrm{A}_{0}, \mathrm{~A}_{1}$ and $\mathrm{A}_{2}$; parameter $E_{\infty}$ the instantaneous elastic modulus; $E_{0}$ the static elastic modulus; $\mathrm{k}$ and $\mathrm{h}$ are the exponents of the parabolic dampers $(1>\mathrm{h}>\mathrm{k}>0)$ and $\delta$ a positive adimensionnal 
coefficient balancing the contribution of the first damper in the global behavior. In that pavement section, the GB3 Huet Sayegh Poison ratio used is $v=0.35$ and the modulus coefficients fitted are: $\mathrm{E}_{0}=40 \mathrm{MPa}, \mathrm{E}_{\infty}=32800 \mathrm{Mpa}, \mathrm{h}=0.71, \mathrm{k}=0.213, \quad \delta=2.2, \mathrm{~A}_{0}=3.62941$, $\mathrm{A}_{1}=-0.39557, \mathrm{~A}_{2}=0.00205$. At the French average speed $(72 \mathrm{~km} / \mathrm{h})$ and the French average temperature $\left(15^{\circ} \mathrm{C}\right)$, the time-frequency equivalence assumption gives an asphalt equivalent modulus $\left(15^{\circ} \mathrm{C}-10 \mathrm{~Hz}\right)$ equal to $13000 \mathrm{MPa}$. With $\mathrm{FABAC}$ devices the speed is $7 \mathrm{~km} / \mathrm{h}$, that is to say 10 times less than the French average speed. As the ratio between the speed of the load and the frequency is also supposed to be constant (Peyronne \& Caroff, 1984), in a first approximation, the frequency taken into account for the $\mathrm{E}$ modulus determination is $1 \mathrm{~Hz}$. Therefore, for pavement elastic calculus, the equivalent GB3 modulus value at $15^{\circ} \mathrm{C}$ is assumed to be $\mathrm{E}\left(15^{\circ} \mathrm{C}-1 \mathrm{~Hz}\right)=8500 \mathrm{MPa}$ and, for a greater temperature, $\mathrm{E}\left(30^{\circ} \mathrm{C}-1 \mathrm{HZ}\right)=1100 \mathrm{MPa}$.

To get mechanical informations near each joint, several sensors have been introduced.

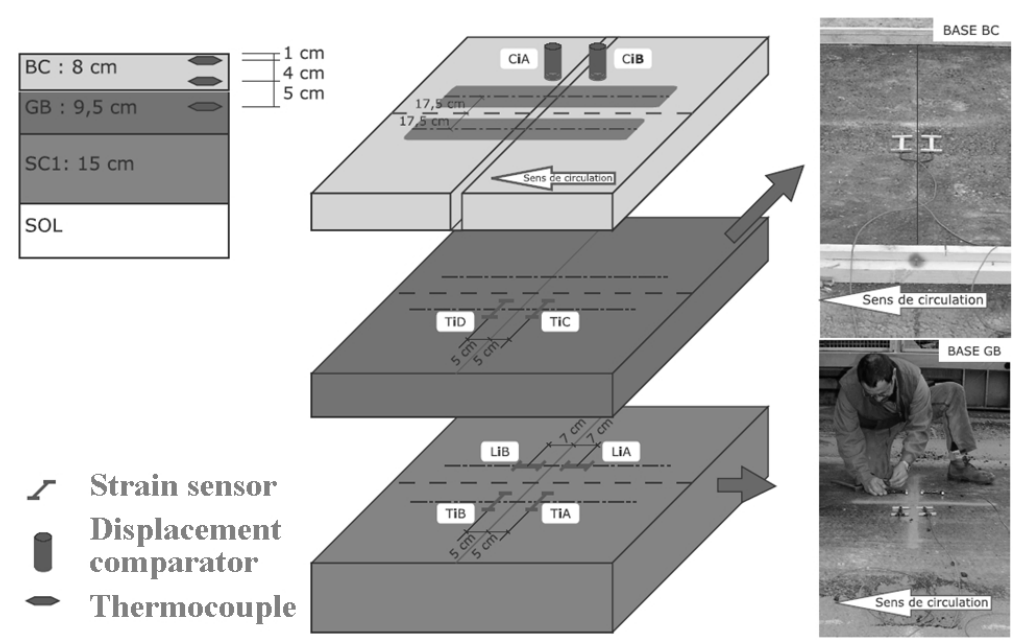

Figure4. Instrumentation of the "i" joint of the composite pavement test section (Pouteau, 2004a)

On Figure 4, one can see that three thermal gages have been used for the measurement of cement and asphalt material temperatures. $\mathrm{CiA}$ and $\mathrm{CiB}$ are supposed to give informations on possible relative displacements between the $\mathrm{BC}$ layer and the GB layer. $\mathrm{LiA}, \mathrm{LiB}, \mathrm{TiA}$ and $\mathrm{TiB}$ denote respectively the two longitudinal and transversal strain sensors that have been put on the bottom of the GB3 at $5 \mathrm{~cm}$ both side of the joint number "i". TiC and TiD denote the two longitudinal strain sensors that have been put at the bottom of the $\mathrm{BC}$ at $5 \mathrm{~cm}$ both side of the joint.

To test the effect of a shot basting interface treatment with the help of the two FABAC machines, two similar environmental tests have been performed on two different types of interface (shot basted or not) between cement overlay and the asphalt layer. Only joints initially perfectly bonded have been loaded. The first test has been done during summer, loading joints number 3 and 7. The second test have been done during winter, loading joints number 2 and 6 (Fig. 3).

\section{INVESTIGATION TOOLS AND RESULTS}

In that section, gage results for the 4 joints tested (J2, J6 and J3, J6) (Fig.3) are first presented. Then a non destructive method and its results are given. The experiment ends with a coring campaign which gives the opportunity to analyze the last phase of life of this pavement section.

\subsection{Gage results and interpretation}

The thermal gages indicated that the winter test of joint 2 and 6 has been made at a temperature contained between 5 to $15^{\circ} \mathrm{C}$. The summer test of joints number 3 and 7 have been tested at 16 to $30^{\circ} \mathrm{C}$ before and after the heat wave of summer 2003 (Fig. 3).

Relative displacement measurements between cement and asphalt layers ( $\mathrm{CiA}$ and $\mathrm{CiB}$ ) gave values in the range of the gage resolution. Unfortunately, these sensors were not well located to be sensible to the delamination process and no useful data provided by them (Pouteau, 2004a). Thus, during the pavement building and the tests a lot of strain gages at the bottom of asphalt 
layers have been unfortunately disabled. Here-under only results on TiC and TiD transversal strain measurements at the bottom of the BC layers can be used (Fig. 5).

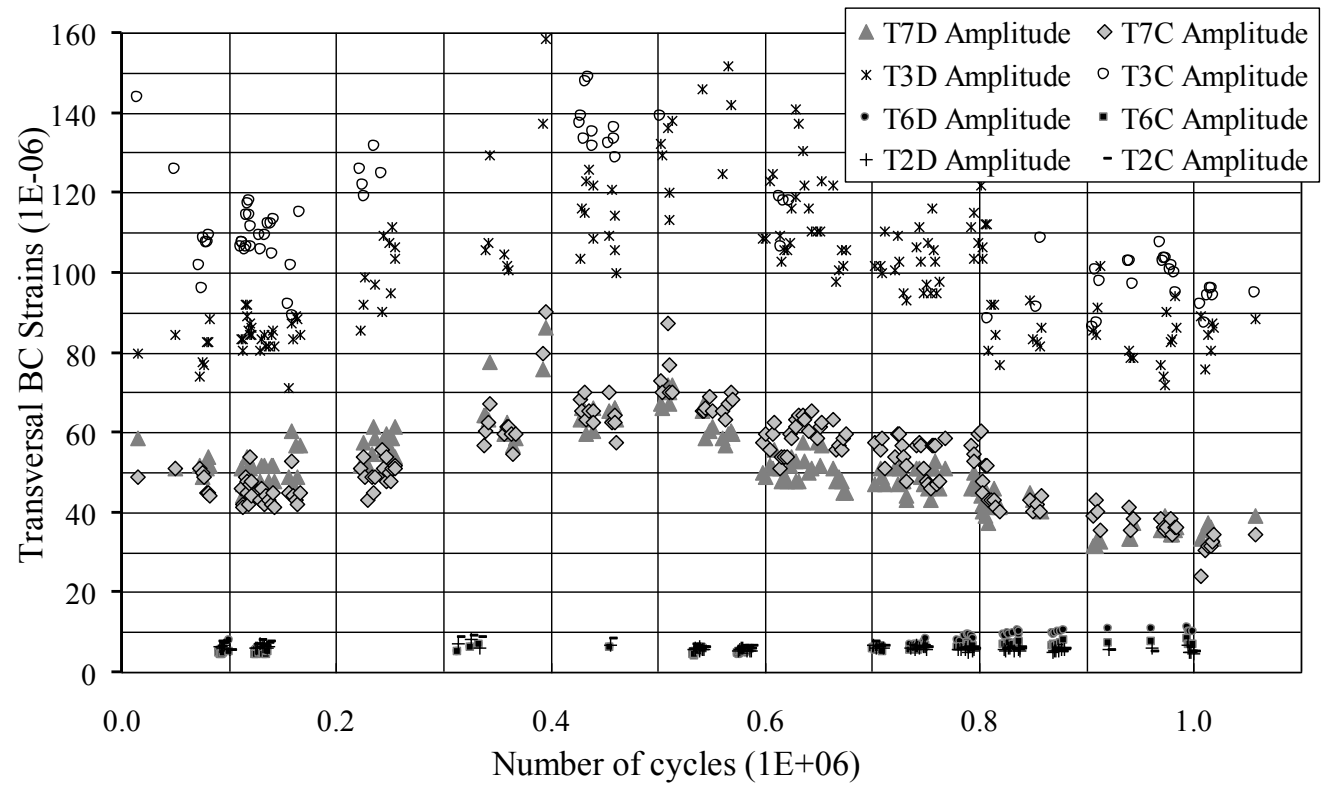

Figure5. Transversal strains at the bottom of the concrete cement layer for joints 2,3,6,7 (Pouteau, 2004a)

Figure 5 shows that there is a sharp difference between winter tests (joints number 2 and 6 ) and summer tests (joints number 3 and 7) in terms of transversal strain at the bottom of the BC layer. These experimental strain results have been compared to calculation without any discontinuity assumption (that is to say bounding hypothesis and no joint or crack modelling). Viscoelastic calculus made with ViscoRoute software that integrates Huet Sayegh law (equation1) (Duhamel et al., 2005) shows that the viscoelasticity of the asphalt material layer does not affect so much the structure behavior for the speed and the different temperature values that have been measured during the tests. Both elastic and viscoelastic calculus made for the asphalt material at $15^{\circ} \mathrm{C}$ and $30^{\circ} \mathrm{C}$ give higher transversal strain values than longitudinal ones at the bottom of the $\mathrm{BC}$ layer. For winter tests at $15^{\circ} \mathrm{C}$, pavement calculus, under only one load, give strain transversal value around $10.10^{-6}$, while at $30^{\circ} \mathrm{C}$ for summer tests, they give $50.10^{-6}$ to $60.10^{-6}$ values depending on the elastic or viscoelastic calculus assumptions (\$2.2). These values are in same range of values than those obtained on (Fig.5) at the initial state of joints number 2, 6 and 7.

In addition, for summer tests, the transversal strains at the bottom of the $\mathrm{BC}$ layer of the joint 3 (not shot basted) have greater values compared to those obtained for the joint 7 (shot basted). All these transversal strain values increase until 0.45 million cycle loadings before decreasing. Increase of strain fits with a growing of debounding interface. Strain decreasing can be explained by a vertical crack initiation at the bottom of the $\mathrm{BC}$ layer, under the wheel path. On the contrary, during the winter environmental conditions, no great strain differences can be founded between joint 2 (not shot basted) and joint 6 (shot basted). The only difference observed is that the strain field of joint 6 seems to increase a little until the end of the test.

\subsection{Non destructive "Colibri" results}

To investigate on the evolution of the pavement test section and the durability of the bond of its interface layers, a non destructive method has been used with the help of the seismic Colibri device. This method consists on beating the structure with a hammer. Then the seismic pavement response by means of an accelerometer is measured. Different investigations have been made to find a UTW Colibri bounding indicator. All details can be found in (Pouteau, 2004a) (Pouteau et al., 2006b). To summarize, the best UTW Colibri bounding indicator was found for the $1025 \mathrm{~Hz}$ to $1318 \mathrm{~Hz}$ range of frequencies. It has been denote $\mathrm{D}_{\text {col }}(1025,1318)$. That method was used on initial bounding joint 2, 3, 6, 7, 8, 9 and initial delaminated joint 1, 4 and 5 (Fig. 3). It has been possible to give typical bounding or delaminated signal envelopes (Fig.6). With that 
reference signals, the four joints tested have been investigated at different loading states among two positions of the wheel path. Here under, Colibri indicator curves between the two wheel paths (JiPC, i number of the joint) are presented for joint 7, 3, 6 and 2 on Figures 6 to 9 at different positions from the joint. JiPCinit indicates the initial state of the joint. JiPC $250 \mathrm{~m}$, JiPC500m and JiPC1M indicate respectively the $0.25,0.5$ and 1 million of cycle loadings. They are quite similar to those obtained under the wheel path (Pouteau, 2004a).

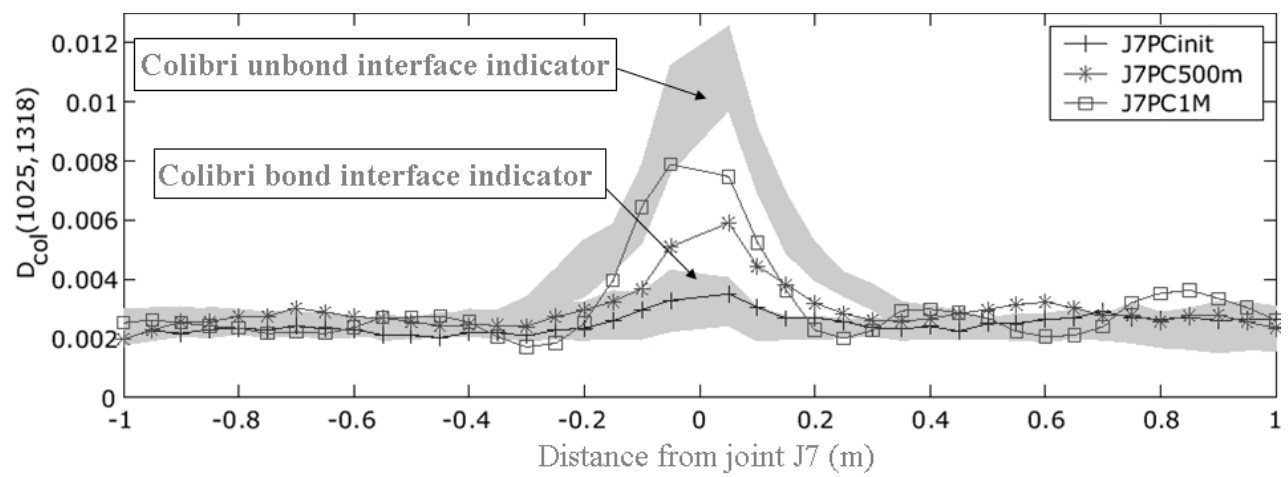

Figure6. Evolution of the bond interface indicator of joint 7 (shot blasted - hot $\mathrm{T}^{\circ} \mathrm{C}$ ) (Pouteau, 2004a)

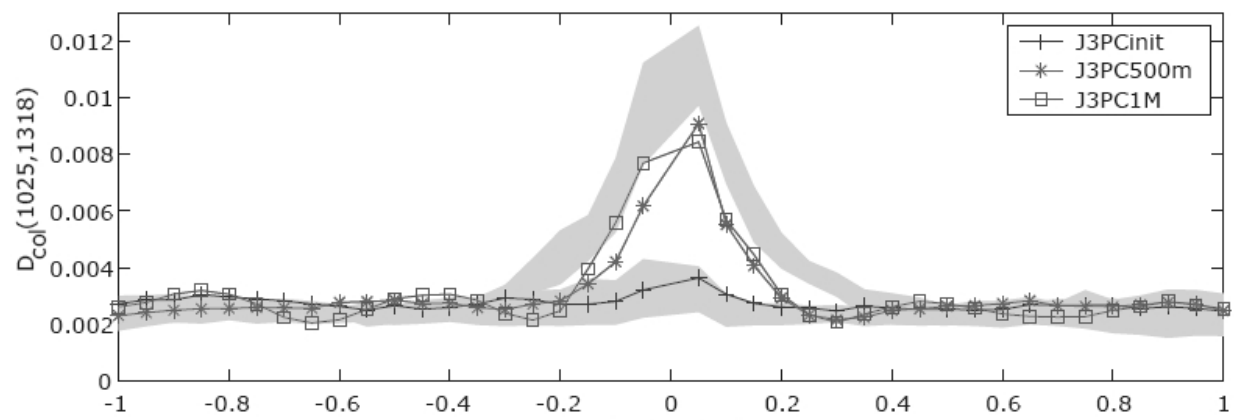

Figure7. Evolution of the bond interface indicator of joint 3 (not shot blasted - hot $\mathrm{T}^{\circ} \mathrm{C}$ ) (Pouteau, 2004a)

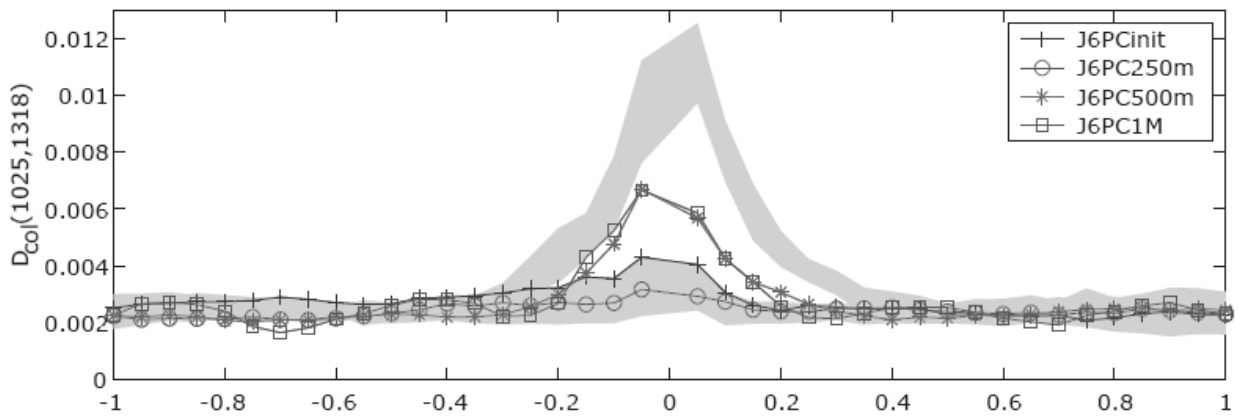

Figure8. Evolution of the bond interface indicator of joint 6 (shot blasted - low $\mathrm{T}^{\circ} \mathrm{C}$ ) (Pouteau, 2004a)

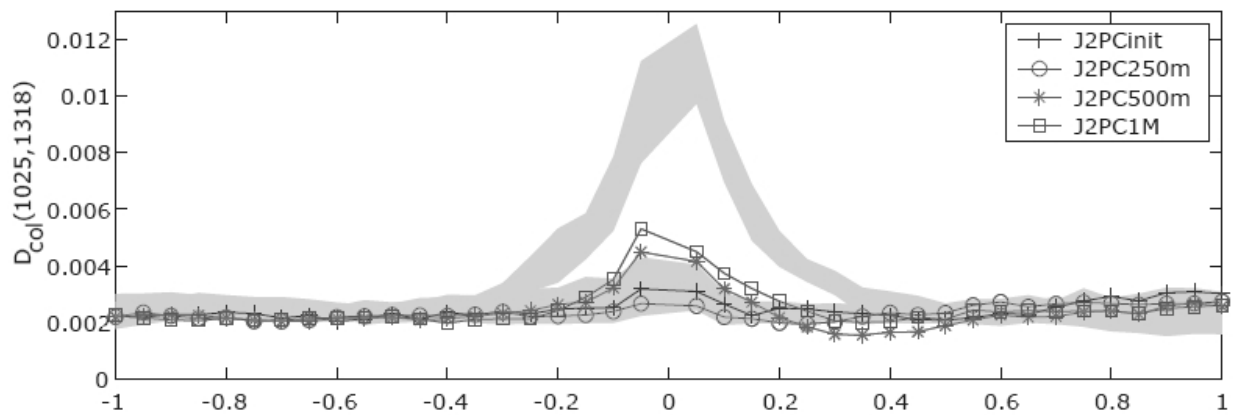

Figure9. Evolution of the bond interface indicator of joint2 (not shot blasted - low T ${ }^{\circ} \mathrm{C}$ ) (Pouteau, 2004a) 
From these non destructive results (Fig 6 to 9), it is clear that failure mechanisms have been located around the joint. On these signals, it was difficult to really notice at the end of the million cycles of loadings the benefit of the shot blasting interface treatment on bounding conditions. Nerveless it might be observed that the summer conditions have been the worst conditions for the long lasting composite pavement life (Fig 6) (Fig 7). For those high temperatures, the shot blasting interface treatment (Fig 6) seems to delay the failure debounding process between the BC and the GB3 layers. Laboratory fatigue test data have confirmed that the shot blasting treatment of interface between cement and asphalt is important for the long lasting bond life (Pouteau et al., 2004b). But in relation to Colibri measurements that have been made on a real experimental pavement of the French national road number 4 (RN4) (Pouteau et al., 2006b), at this state of this study, it is hard to conclude that the Colibri signal evolution represents precisely delamination phenomenon or more generally failures among the material layers.

\subsection{Core results}

To add more information about failure, a core sample campaign has been finally made to link Colibri results with bounding core states. For each joint, 8 cores have been extracted at several positions of the wheel path and distance from the joint (Fig. 10). Interface cracking propagation informations and failure mechanisms had to be found out. On Figure 10 are only presented core sample photos that have been taken under the wheel path and on the joint (I), between the two twin wheel path (II) and under the wheel path at $15 \mathrm{~cm}$ before the joint position (D index for joint 2, $\mathrm{C}$ index for joint 6,3 and 7).
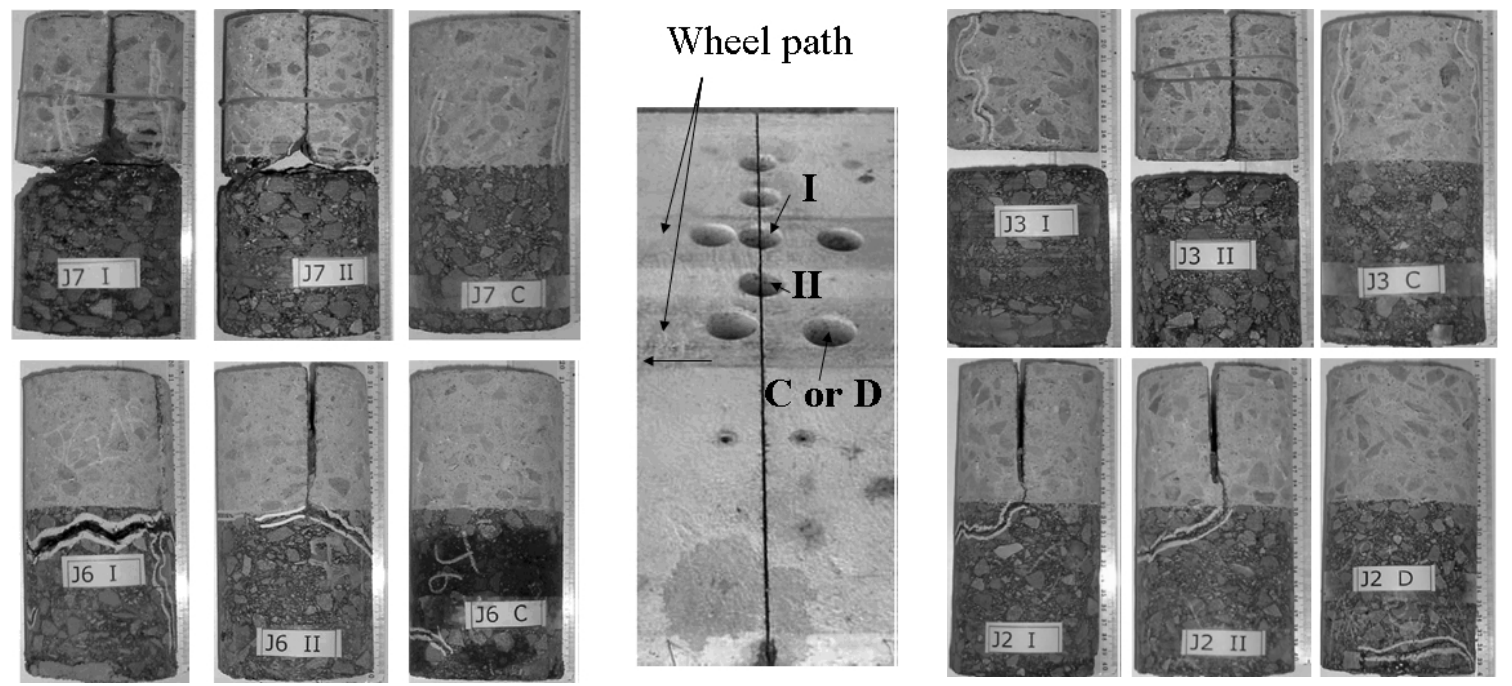

Figure 10. Core sample campaign after 1million loadings for joints number 7, 3, 6 and 3 (Pouteau, 2004a)

First, according to the first assumptions written in the introduction of this paper, Figure 10 shows that the loads of the FABAC devices propagated the crack vertically from the joint to the interface between BC and GB3 layers. This is true for all the type of joints. These vertical cracks located near the two different material layers produce stress singularities (Fig.1).

Concerning joint 7 and 3, it can be noticed that hot temperature conditions of loading (from $15^{\circ} \mathrm{C}$ to $30^{\circ} \mathrm{C}$ ) lead to damage easily the interface between layers near the joint (Fig. 10). For joint 3 which its interface is not shot blasted, it seems that the bonding conditions have not been realized at all. No damages can be seen in its asphalt layer. Under the wheel path, the cement concrete layer has been hardly damaged by vertical cracks coming from the interface even if, far from the joint, there is no delamination observed. These observations can explain the high level of transversal strain measurements at the bottom of the BC layer (Fig.5). For joint 7 which its interface is shot blasted, the top of its GB3 layer have been hardly damaged. It seems that these 
damages have occurred before the delamination and the propagation of the vertical crack along the $\mathrm{BC}$ layer under the wheel path. In these two cases, the great difference of modulus value between these two material layers associated to a thin overlay is an enemy to a long lasting interface bond between these layers near the joint. In that case, the shot blasted interface treatment between BC and GB3 layers is important to ameliorate the long lasting bond life.

On Figure 10, related to joint 6 and 2, it can be observed that the low temperature conditions of loading (from $5^{\circ} \mathrm{C}$ to $15^{\circ} \mathrm{C}$ ) lead to damage the asphalt layer. The bond between the two layers seems to resist. No damages, as vertical cracks, have been observed at the bottom of the $\mathrm{BC}$ layers. The vertical crack coming from the joint propagated in the GB3 layer in a parallel way to the interface between layers. High level of shear stresses is supposed to be found. In that case, the effect of the different interface treatments (shot blasted or not) did not count so much on the conditions of the long lasting bond life compared to the shear mechanical performance of the GB3 layer.

These fatigue tests and this study have to be linked to more data before conclude.

\subsection{Damage scenario}

From all of these experiment observations, temperature effects on the ratio of modulus between the cement and asphalt material and the load positions from the joint seem to be the more damageable effects of the long lasting bond life of such a composite pavement. These first conclusions lead to propose a damage scenario of this composite pavement test section (Fig. 11) (Pouteau, 2004a).

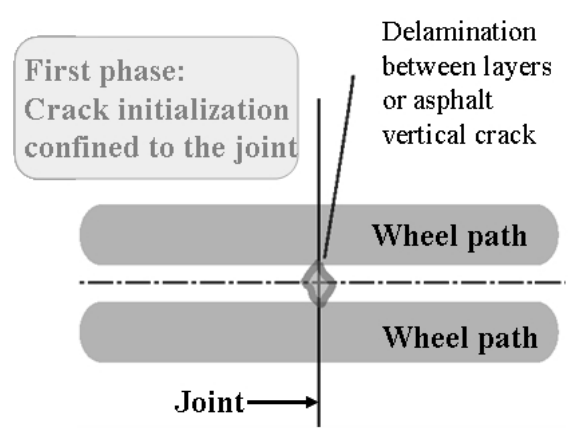

Figure11. Damage scenario

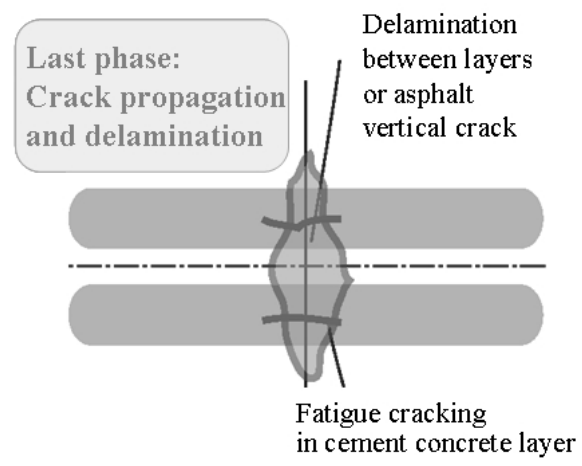

From the core campaign and Colibri measurements, it has been confirmed that the first failures appear upon the joint between the two wheel paths. Then, depending of the temperature, cracks propagate along the joint under the wheel path. They generate a delamination between the BC and the GB3 layers or cracks parallel to the interface in the GB3 layer. Finally, when a delamination between layers exists vertical cracks appear at the bottom of the $\mathrm{BC}$ layer.

\section{PAVEMENT MODELING CONSIDERATIONS}

To add more information on that deterioration process and to get finally failure criteria of such a pavement structure, it is necessary to link these experimental results to careful analyses of the 3D stress field state. Due to existing singular stress fields located near the vertical crack of the cement concrete overlay and the interface of these two different material media (Fig 1), it is hard to analyze easily these 3D stress fields with classical modelling and FEM 3D.

Since 2001, it is proposed at LCPC to develop and make a proper analysis of crack initiation and propagation in such a cracked pavement structures. This approach is destined to be used by engineers. A 3D simplified model (named the Multi-particle Model of Multi-layer Materials, M4) linked to the Boussinesq model for the soil (M4-5nB) has been developed (Tran et al., 2004). It has the advantage of reducing the real $3 \mathrm{D}$ problem to the determination of regular 
plane fields $(x, y)$ per layer and interfaces. M4-5n modelling approach makes possible simple determinations of delamination criteria (Caron et al., 2006). M4-5nB computations are in good accordance compared to 3D FEM results and need less time consuming (Chabot et al., 2005). Several inelastic fields can be introduced as data for the modelling of shrinkage, thermal conditions and debounding effects (Chabot et al., 2007). A software tool is under development.

With that so-called M4-Boussinesq model, it has been proposed to analyze the initial mechanical fields of that in-situ experiment (Chabot et al., 2004). This modelling shows in simplified modelling conditions that, when the load is located at the edge of the joint, the interface pavement composite system is loaded in mixed mode conditions. In fact, it gives maximum shear and normal stress fields at the edge of the crack at the interface between the concrete and the asphalt layers. These results needs to be examined in greater details under real experimental conditions (free edges along the transversal-axis; inclusion of thermal gradient effects in the thin bonded cement concrete layer; real distribution of tire/pavement contact; comparison with instrumentation-based measurements; analysis of visco-elastic effects from asphalt material, etc.) (Chabot et al., 2007). Nevertheless, this modeling finds that the normal interface stress is highly in compression underneath the load and remains significant in tension on the unloaded side. These interface stress fields produce debounding.

To help engineer to find the best realistic and resistant bi-material couple, it is necessary to deepen this work with the help of bi-material specimens controlled with mixed mode laboratory fatigue tests. A first tentative approach has been made for the BC and GB3 materials of this study (Pouteau et al., 2002) (Pouteau, 2004). M4-5n approach help to design the lab specimens for optimizing the delamination of the interface. These lab experiments shown that a shot blasted interface could stop and delay the debounding. But in such a bi-material couple, due to the parasite effect of the visco-elastic behavior of the asphalt material, another specific flexural laboratory tests have to be developed. Those produced by the so-called "Mefisto" device (Vecoven, 1990) or by the new laboratory test proposed at ENPC by (Florence et al., 2004) should be better candidates to these experimental studies.

\section{CONCLUSION}

This study deals with an experimental in-situ performance of a pavement bound interface between a thin cement concrete layer and an asphalt one (Pouteau, 2004). The traffic loading is simulated by means of two LCPC linear Accelerated Loading Facilities, call FABAC devices. These FABAC devices simulate heavy traffic by applying the passage of 6.5 tonne twin axle repeatedly loads. After a million passages of this reference axle on different pavement joints, fatigue damage have been observed. It has occured as well at the interface between layers as in the concrete and the asphalt materials. Transversal strain measurements at the bottom of the BC layer, non-destructive Colibri measurements combined with core sampling after the tests, make it possible to reconstitute a structural deterioration scenario. These tests had shown that the temperature and the position of the load near the joint are the most damageable factors. Especially for hot temperature environmental conditions, it also has being shown that a shot blasting interface treatment delay the delamination between the cement overlay and the asphalt layer. During lab test on bi-material specimen, the effect has been also observed for low temperature.

To find a simple delamination criteria to use and design recommendations, it is proposed to deep the mechanical understandings of this deterioration with the help of a specific modeling and laboratory fatigue bi-material tests. Connected to reflective cracking ALT-APT experience done by (Pérez et al., 2007), these studies help to develop of a laboratory equipment to evaluate the crack propagation of such a cracked pavements. These investigations are proposed to be continuing in relation to a LCPC research program called Fondephy (http://or.lcpc.fr/fondephy).

\section{ACKNOWLEDGEMENT}

Authors acknowledge the financial and technical supports of ATILH (Association Technique de l'Industrie des Liants Hydrauliques) and thank SPECBEA and CIMBETON for their contribution to this study. Authors also acknowledge Gilles Coirier, Thierry Gouy, Jean-Pierre Kerzreho, Patrick Maisonnoeuvre, Gérard Leroy, Jean-Paul Nerfie and Jean-Michel Simonin from LCPC for their experimental technical support. 


\section{REFERENCES}

Autret, P. \& de Boissoudy, A.B. \& Gramsammer J.C., 1987. The circular test track of the Laboratoire Central des Ponts et Chaussées - First Results. Proc. 6th Intern. Conf. on Structural Design of Asphalt Pavements, Ann Arbor, June 13-17 1997, 1 :550-561.

Aunis, J. \& Balay, J. M. 1998. An applied research programme on continuous reinforced concrete pavements: the FABAC project. Proceedings of the $8^{\text {th }}$ International Symposium on Concrete Roads, Lisbon September 13-16 1998.

Caron, J. F. \& Diaz Diaz, A. \& Carreira, R. P. \& Chabot, A. \& Ehrlacher, A. 2006. Multi-particle modelling for the prediction of delamination in multi-layered materials. Composites Sciences and Technology, 66 (6), 755-765.

Chabot, A. \& Tran, Q. D. \& Pouteau B. 2004. Simplified modelling of a cracked composite pavement, First International Elsevier Conference on Failure Analysis, Lisbon July 12-14 2004.

Chabot, A. \& Tran, Q. D. \& Ehrlacher, A. 2005. A simplified modeling for cracked pavements - Modèle simplifié pour le calcul des chaussées, Bulletin des Laboratoires des Ponts et chaussées (258-259) : 105-120.

Chabot, A. \& Tran Q. D. \& Ehrlacher A. 2007. A modeling to understand where a vertical crak can propagate in pavements. In Taylor \& Francis Group Proceedings, International Conference on Advanced Characterization of Pavement and Soil Engineering Materials, Athens June 20-22 2007 1: 431-440.

CIMbéton 2004. Le Béton de Ciment Mince Collé "BCMC". Collection TechniqueCIMbeton T60, $2^{\text {nd }}$ edition.

Cole, L. W. \& Mack, J. W. \& Packard R. G. 1998. Whitetopping and ultra-thin whitetopping the US experience. 8th International Symposium on Concrete Roads, 1998.

Duhamel, D. \& Chabot, A. \& Tamagny, P. \& Harfouche, L. 2005. Viscoroute: Visco-elastic modeling for asphalt pavements - Viscoroute : Modélisation des chaussées bitumineuses. Bulletin des Laboratoires des Ponts et chaussées (258-259) : 89-103.

Florence, C. \& Foret, G.. \& Tamagny, P. \& Sener, J.Y. \& Ehrlacher, A. 2004. Design of a new laboratory test simulating the reflective cracking in Pavements with cement treated bases. In RILEM Proceedings PRO 37, Fifth Internat.l RILEM Conf. Cracking in Pavements, Limoges May 5-8 2004: 147-154.

Hornych, P. \& Kerzreho, J. P. \& Chabot, A. \&. Bodin, D. \& Balay, J. M. 2008. The LCPC's ALT facility contribution to pavement cracking knowledge. Proposed to the Sixth International RILEM Conference Cracking in Pavements, Chicago June 16-18.

LCPC-SETRA (décembre) 1994. Conception et dimensionnement des structures de chaussée. Guide Technique LCPC-SETRA.

Peyronne, C. \& Caroff, G., 1984. Cours des routes - Dimensionnement des chaussées. Paris: Presses de l'Ecole Nationale des Ponts et Chaussées (ISBN 2-85978-066-1).

Pérez S. A. \& Balay J. M. \& Tamagny P. \& Petit Ch. 2007. Accelerated pavement testing and modeling of reflective cracking in pavements. Engineering Failure Analysis, 14 (8): 1526-1537.

Pouteau B. \& Chabot A. \& De Larrard F., 2002. Etude en laboratoire du collage béton/ matériaux bitumineux". Matériaux 2002, 21-25 octobre, Tours.

Pouteau, B. 2004a. Durabilité mécanique du collage blanc sur noir dans les chaussées. PhD thesis of the Ecole Centrale de Nantes (http://www.lcpc.fr/msc).

Pouteau, B. \& Balay, J.-M. \& Chabot A. \& De Larrard F. 2004b. Fatigue test and mechanical study of adhesion between concrete and asphalt. $9^{\text {th }}$ International Symposium on Concrete Roads, Istanbul 3-6 April 2004.

Pouteau, B. \& Chabot, A. \& De Larrard, F. \& Balay J. M. 2006a. Mécanique des chaussées Béton sur grave-bitume, Etude de la tenue du collage entre béton et enrobé sur chaussée expérimentale $\left(1^{\text {re }}\right.$ partie). Revue Générale des Routes et des Aérodromes (RGRA) (847) : 85- 90.

Pouteau, B. \& Simonin J. M. \& De Larrard F. 2006b. Mécanique des chaussées Béton sur grave-bitume, Suivi du chantier expérimental RN4 de chaussée composite ( $2^{\mathrm{ème}}$ partie). Revue Générale des Routes et des Aérodromes (RGRA) (848) : 62-66.

Qi, X. \& Mitchell, T. \& Sherwood, J. A. 2004. Evaluation of UTW fatigue cracking using FHWA's Accelrated Loading Facility. In RILEM Proceedings PRO 37, Fifth International RILEM Conference Cracking in Pavements, Limoges May 5-8 2004: 37-44.

Tran, Q. D. \& Chabot, A. \& Ehrlacher, A. \& Tamagny, P. 2004. A simplified modelling for cracking in pavements. In RILEM Proceedings PRO 37, Fifth International RILEM Conference Cracking in Pavements, Limoges May 5-8 2004: 299-306.

Vecoven 1990. Crack reflection treatment testing machine for hydraulic treated pavement. Revue Générale des Routes et des Aérodromes (RGRA) (680) : 19-21. 